\title{
JNPH
}

Volume 6 No. 2 (Oktober 2018)

(C) The Author(s) 2018

\section{ANALISIS PERSONAL HYGIENE PENJAMAH DAN SANITASI MAKANAN JAJANAN DI SEKOLAH DASAR KECAMATAN GADING CEMPAKA KOTA BENGKULU}

\section{ANALYSIS OF PERSONAL HYGIENE HANDLERS AND SNACK FOOD SANITATION AT THE ELEMENTARY SCHOOL OF GADING CEMPAKA DISTRICT, BENGKULU CITY}

\author{
APLINA KARTIKA SARI, HALIMATUSA'DIAH \\ POLITEKNIK KESEHATAN KEMENTERIAN KESEHATAN BENGKULU, JURUSAN \\ KESEHATAN LINGKUNGAN, \\ JALAN INDRAGIRI NOMOR 3 PADANG HARAPAN BENGKULU \\ E-mail : keslingpoltek@gmail.com
}

\begin{abstract}
ABSTRAK
Makanan jajanan telah menjadi bagian dari keseharian anak-anak sekolah dan sangat banyak produsen jajanan anak yang tidak memperhatikan keamanan produknya, maka tidak mustahil akan menimbulkan beberapa kerugian diantaranya makanan jajanan yang kurang terjamin kebersihannya akan menyebabkan penyakit pada saluran pencernaan. Penelitian ini bertujuan untuk diketahuinya personal hygiene penjamah dan sanitasi makanan jajanan di Sekolah Dasar Kecamatan Gading Cempaka Kota Bengkulu. Penelitian ini bersifat deskriptif kuantitatif, yaitu riset yang menggambarkan atau menjelaskan suatu masalah yang hasilnya dapat digeneralisasikan. Populasi dan sampel dalam penelitian ini adalah penjamah makanan jajanan di Sekolah Dasar Kecamatan Gading Cempaka Kota Bengkulu berjumlah 16 Sampel. Pengolahan data yang terkumpul dari hasil lapangan diolah dan disajikan dalam bentuk tabel distribusi frekuensi dan narasi. Teknik Analisis data dilakukan secara univariat dengan tujuan menjelaskan atau mendeskripsikan karakteristik setiap variabel penelitian. Hasil analisis Personal hygiene penjamah makanan jajanan lebih dari sebagian besar $(84,6 \%)$ tidak memenuhi syarat dan Sanitasi makanan jajanan sebagian besar $(61,54 \%$.) tidak memenuhi syarat. Diharapkan kepada penjamah/pedagang makanan jajanan agar melakukan upaya perbaikan dalam hal personal hygiene seperti mencuci tangan dengan sabun sebelum menjamah makanan, memakai alat/perlengkapan atau dengan alas tangan, menggunakan celemek, dan senantiasa menjaga membersikan. Untuk sanitasi makanan jajanan diupayakan agar menggunakan lap bersih untuk mengeringkan peralatan dan melengkapi fasilitas sanitasi yang belum tersedia atau yang belum memenuhi syarat.
\end{abstract}

Kata Kunci : Personal Hygiene, Sanitasi Makanan Jajan

\begin{abstract}
Snack food has become part of the daily lives of school children and there are so many snack food producers who do not pay attention to the safety of their products, it is not impossible to incur some disadvantages including snacks that are not guaranteed to be clean will cause
\end{abstract}


disease in the digestive tract. This study aims to know personal hygiene handlers and snack food sanitation at the Elementary School of Gading Cempaka District, Bengkulu City. This research is quantitative descriptive, which is research that describes or explains a problem that results can be generalized. The population and sample in this study were snacks food handlers in the Elementary School of Gading Cempaka Subdistrict, Bengkulu City, totaling 16 samples. Data processing collected from field results is processed and presented in the form of frequency distribution and narrative tables. Data analysis techniques were carried out univariately with the aim of explaining or describing the characteristics of each research variable. The results of the analysis of personal hygiene food handlers more than most $(84.6 \%)$ did not meet the requirements and snack food sanitation most (61.54\%) did not meet the requirements. It is expected that food handlers / traders to make improvements in terms of personal hygiene such as washing hands with soap before touching food, using tools / equipment or with hand pads, using aprons, and always keep cleaning. Food sanitation is sought to use clean cloths to dry equipment and equip sanitation facilities that are not yet available or that do not meet the requirements.

\section{Keywords: Personal Hygiene, Snack Food Sanitation}

\section{PENDAHULUAN}

Penyakit bawaan makanan (Foodborne disease) adalah penyakit yang ditimbulkan oleh makanan yang terkontaminasi.(Susana, 2008). Volk dan Wheller (1993) menyatakan bahwa foodborne disease yang disebabkan oleh bakteri dapat dibagi menjadi dua kelompok besar, yaitu infeksi makanan dan keracunan makanan. Infeksi makanan terjadi karena konsumsi makanan mengandung bakteri hidup yang mampu bersporulasi di dalam usus dan menimbulkan penyakit. Sedangkan keracunan makanan tidak disebabkan tertelannya bakteri hidup, melainkan akibat masuknya toksin atau substansi beracun yang disekresi ke dalam makanan.

Menurut Syahrurachman,A (2010), terdapat berbagai macam mikroorganisme yang dapat mencemari makanan, diantaranya adalah salmonella. Bakteri ini merupakan agen penyebab bermacam-macam infeksi, mulai dari gastroenteritis yang ringan sampai dengan bakteremia disertai demam tifoid.

Data WHO tahun 2003 memperkirakan terdapat 17 juta kasus demam tifoid di seluruh dunia dengan insidensi 600.000 kasus kematian tiap tahunnya (World Health Organisation, 2003). Demam tifoid masih menjadi masalah kesehatan di negara- negara berkembang terutama Indonesia. Prevalensi demam typhoid di Indonesia termasuk tertinggi dibandingkan dengan negara-negara lain di dunia. Di Indonesia, demam tifoid merupakan masalah kesehatan masyarakat dengan kejadian antara 350-810 kasus per 100.000 penduduk setiap tahun. Profil Kesehatan Indonesia tahun 2010 menyatakan demam tifoid atau paratifoid menempati urutan ke 3 dari 10 penyakit terbanyak pasien rawat inap di rumah sakit tahun 2010 yaitu sebanyak 41.081 kasus yang meninggal 274 orang dengan Case Fatality Rate sebesar 0,67 (http://www.depkes.go.id).

Penyakit tersebut sangat erat hubungannya dengan higiene perorangan yang kurang baik, sanitasi lingkungan yang kurang kondusif seperti penyediaan air bersih yang kurang memadai, pembuangan sampah dan kotoran manusia yang tidak memenuhi syarat kesehatan, pengawasan makanan dan minuman yang belum sempurna serta fasilitas kesehatan yang tidak terjangkau oleh sebagian masyarakat (Dolman, Soeharyo, 1994).

Makanan jajanan anak merupakan sumber potensial yang mempunyai nilai komoditas \& menunjang perekonomian dalam jalur informal karena banyak jajanan anak yang dibuat dalam skala kecil sebagai industri rumahan. Jajanan anak telah menjadi 
bagian dari keseharian anak. Hampir semua anak diberi uang jajan oleh orang tuanya. Padahal, belum tentu jajanan yang tersedia itu sesuai dengan standar mutu \& jaminan bahwa jajanan tersebut aman \& layak untuk dikonsumsi. Saat ini, sangat banyak produsen jajanan anak yang tidak memperhatikan keamanan produknya. Mereka lebih memikirkan keuntungan yang dihasilkan, yaitu dengan modal sekecil-kecilnya tetapi mendapatkan untung yang sebesar-besarnya dengan tanpa memperhatikan aspek keamanan \& keselamatan konsumen. (Hukum-Kesehatan.web.id).

Pada golongan usia sekolah khususnya usia Sekolah Dasar (SD), waktu yang dimiliki lebih banyak dihabiskan di luar rumah baik di sekolah maupun tempat bermain. Hal ini mempengaruhi kebiasaan waktu makan, yaitu pada umumnya pada waktu lapar anak lebih suka jajan. Selain itu, bertambahnya jumlah kaum ibu yang harus bekerja untuk menunjang pendapatan keluarga, sehingga waktu yang tersisa untuk menyiapkan makanan di rumah berkurang. Dari aspek kesehatan akan positif bila anak dapat memilih makanan jajanan yang cukup nilai gizi dan terjamin akan kebersihannya. Namun bila makanan jajanan dibeli di sembarang tempat, maka tidak mustahil akan menimbulkan beberapa kerugian diantaranya makanan jajanan yang kurang terjamin kebersihannya akan menyebabkan penyakit pada saluran pencernaan ( Sihadi, 2004 )

\section{METODE PENELITIAN}

Penelitian ini bersifat deskriptif kuantitatif, yaitu riset yang menggambarkan atau menjelaskan suatu masalah yang hasilnya dapat digeneralisasikan. Tempat lokasi penelitian di Sekolah Dasar Kecamatan Gading Cempaka Kota Bengkulu dengan alokasi waktu penelitian selama 3 bulan

\section{HASIL PENELITIAN}

Berdasarkan hasil pemeriksaan personal hygiene dan sanitasi makanan pada pedagang makanan jajanan yang dilakukan mulai September sampai dengan November 2017 di Sekolah Dasar Kecamatan Gading Cempaka Kota Bengkulu.

1. Hasil Pemeriksaan Personal Hygiene Pedagang Makanan Jajanan di Sekolah Dasar Kecamatan Gading Cempaka Kota Bengkulu

Tabel 1. Distribusi Frekuensi Hasil Pemeriksaan Personal Hygiene Pedagang Makanan Jajanan di Sekolah Dasar Kecamatan Gading Cempaka Kota Bengkulu Tahun 2017

\begin{tabular}{lcc}
\hline Personal Hygiene & Frekuensi & Persentase \\
\hline $\begin{array}{l}\text { Memenuhi Syarat } \geq \\
65 \%\end{array}$ & 2 & 15,4 \\
\hline $\begin{array}{l}\text { Tidak Memenuhi } \\
\text { Syarat }<65 \%\end{array}$ & 11 & 84,6 \\
\hline \multicolumn{1}{c}{ Total } & 13 & 100 \\
\hline
\end{tabular}

Berdasarkan table 1. dapat diketahui bahwa personal hygiene pedagang makanan jajanan di sekolah dasar kecamatan gading cempaka yang memenuhi syarat sebanyak 2 $(15,4 \%)$ dan yang tidak memenuhi syarat sebanyak $11(84,6 \%)$.

2. Hasil Pemeriksaan Sanitasi Makanan Jajanan di Sekolah Dasar Kecamatan Gading Cempaka Kota Bengkulu

\section{Tabel 2. Distribusi Frekuensi Hasil Pemeriksaan Sanitasi Makanan Jajanan di Sekolah Dasar Kecamatan Gading Cempaka Kota Bengkulu Tahun 2017}

\begin{tabular}{lcc}
\hline $\begin{array}{l}\text { Sanitasi Makanan } \\
\text { Jajanan }\end{array}$ & Frekuensi & Persentase \\
\hline $\begin{array}{l}\text { Memenuhi Syarat } \geq \\
65 \%\end{array}$ & 5 & 38,46 \\
\hline $\begin{array}{l}\text { Tidak Memenuhi } \\
\text { Syarat }<65 \%\end{array}$ & 8 & 61,54 \\
\hline \multicolumn{1}{c}{ Total } & 13 & 100 \\
\hline
\end{tabular}

Berdasarkan tabel 2. dapat diketahui bahwa sanitasi makanan jajanan di sekolah dasar kecamatan gading cempaka yang memenuhi syarat sebanyak $5(38,46 \%)$ dan 
yang tidak memenuhi syarat sebanyak 8 $(61,54 \%)$.

\section{PEMBAHASAN}

1. Personal Hygiene Pedagang Makanan Jajanan di Sekolah Dasar Kecamatan Gading Cempaka Kota Bengkulu

Berdasarkan tabel 1. dapat diketahui bahwa personal hygiene pedagang makanan jajanan di sekolah dasar Kecamatan Gading Cempaka sebagian besar $(84,6 \%)$ tidak memenuhi syarat. Hal ini disebabkan karena pedagang/penjamah makanan sebanyak $69,2 \%$ tidak mencuci tangan dengan sabun sebelum menjamah makanan, $76,9 \%$ pada saat menjamah makanan tidak memakai alat/perlengkapan atau dengan alas tangan, $69,2 \%$ tidak menggunakan celemek, dan $76,9 \%$ tidak memiliki kuku pendek dan bersih.

Lebih dari sebagian penjamah yang tidak mencuci tangan saat observasi dikarenakan sudah terbiasa tidak mencuci tangan. Ditempat-tempat berjualan yang tersedia tempat air bersih juga ditemukan pedagang makanan jajanan yang tidak mencuci tangannya karena malas harus mondar-mandir setiap akan menangani makanan, terlebih saat pembeli yang hampir seluruhnya anak-anak datang dalam jumlah banyak ketika waktu istirahat. Saat anak-anak tersebut berebut untuk membeli makanan jajanan dan pedagang sibuk melayani, pedagang tersebut tidak mencuci tangannya, padahal selalu memegang uang setelah selesai menangani makanan lalu kembali menangani makanan untuk pembeli berikutnya. Hal tersebut dapat menyebabkan kontaminasi silang terhadap makanan yang disajikan atau diproses. Kontaminasi silang dapat menyebabkan makanan tercemar sehingga kuman penyebab diare masuk ke dalam tubuh dan menginfeksi saluran pencernaan (Arisman, 2009)

Sebagian besar pedagang memiliki kuku yang panjang dan kehitaman serta tidak menggunakan alat atau alas tangan dalam menjamah makanan sehingga dapat memindahkan agen penyakit ke makanan (Purnawijayanti, 2001).

2. Sanitasi Makanan Jajanan di Sekolah Dasar Kecamatan Gading Cempaka Kota Bengkulu

Berdasarkan table 2. dapat diketahui bahwa sanitasi makanan jajanan di sekolah dasar kecamatan gading cempaka lebih dari sebagian $(61,54 \%)$ tidak memenuhi syarat. Sanitasi makanan meliputi sanitasi peralatan, air yang digunakan, penyajian dan fasilitas sanitasi.

Hasil observasi terhadap sanitasi peralatan di sekolah dasar Kecamatan Gading Cempaka menunjukkan bahwa lebih dari sebagian $(61,5 \%)$ memenuhi syarat. Meskipun secara umum kebersihan peralatan sudah memenuhi syarat, masih ditemukan adanya pedagang makanan jajanan yang tidak mengeringkan peralatan dengan lap yang bersih. Penggunaan lap yang sudah kotor untuk mengelap peralatan dapat mencermari makanan karena mikroorganisme dapat berpindah ke peralatan tersebut (Setyorini, 2013).

Hasil penelitian terhadap penggunaan air dalam mengolah makanan bahwa lebih dari sebagian $(53,8 \%)$ pedagang menggunakan air galon dan hampir sebagian $(46,2 \%)$ menggunakan air yang dimasak sendiri.

Hasil observasi terhadap penyajian makanan jajanan menunjukkan bahwa sebagian besar $(84,6 \%)$ pedagang makanan jajanan memiliki cara penyajian yang memenuhi syarat. Pada distribusi frekuensi penyajian, semua persyaratan mengenai sanitasi penyajian dapt dipenuhi dengan baik oleh pedagang.

Fasilitas sanitasi lebih dari sebagian $(69,2 \%)$ tidak memenuhi syarat. Hal ini disebabkan hampir sebagian besar fasilitas sanitasi yang tidak terpenuhi yaitu tidak ada tempat air bersih, tidak tersedianya tempat penyimpanan bahan makanan, makanan jadi dan peralatan, tidak tersedianya tempat sampa 
yang memenuhi syarat.

\section{KESIMPULAN}

Hasil penelitian yang telah dilakukan, dapat diambil simpulan sebagai berikut:

1. Personal hygiene pedagang makanan jajanan di sekolah dasar kecamatan gading cempaka lebih dari sebagian $(84,6 \%)$ tidak memenuhi syarat.

2. Sanitasi makanan jajanan di sekolah dasar kecamatan gading cempaka sebagian besar $(61,54 \%$.) tidak memenuhi syarat.

\section{SARAN}

Diharapkan kepada pedagang makanan jajanan agar melakukan upaya perbaikan dalam hal personal hygiene seperti mencuci tangan dengan sabun sebelum menjamah makanan, memakai alat/perlengkapan atau dengan alas tangan, menggunakan celemek, dan senantiasa menjaga membersikan. Untuk sanitasi makanan jajanan diupayakan agar menggunakan lap bersih untuk mengeringkan peralatan dan melengkapi fasilitas sanitasi yang belum tersedia atau yang belum memenuhi syarat.

\section{DAFTAR PUSTAKA}

Badan Litbangkes Depkes RI. 2008. Laporan Riset Kesehatan Dasar Nasional.Departemen Kesehatan Republik I n d o n e s i a, J a k a r t a, (http://www.k4health.org)

Badan Standar Nasional.2011. Batas Maksimum Cemaran Mikroba dalam Pangan, BSN.

Bulan,A.F dan Marendra,Z. 2010. Smart parent : Pandai mengatur menu dan Tanggap Saat Anak Sakit, Gagas Media, Jakarta.

Chandra, B.2007. Pengantar Kesehatan Lingkungan, Widyastuti, P (Ed), EGC, Jakarta.
Gibson,JM. 1996.Mikrobiologi dan Patologi Modern untuk Perawat, Asih.Y (ed) EGC, Jakarta.

Hukum-Kesehatan.web.id. 2013. Aspek Hukum Bahan Tambahan Pada Jajanan Anak,http://id.shvoong.com/medicineandhealth/epidemiology-public-health.

Hukum-Kesehatan.web.id. 2013. Awas jajanan Anak SD Terkontaminasi Bakteri http://id.shvoong.com/medicineandhealth/epidemiology-public-health.

Kementerian Kesehatan Republik Indonesia.2011. Profil Kesehatan Indonesia 2010, Kementrian Kesehatan Republik Indonesia, Jakarta (http://www.depkes.go.id)

Sihadi.2004. Makanan Jajanan Bagi Anak Sekolah. Jurnal Kedokteran YARSI.

Syahrurachman, A.,dkk.2010. Buku Ajar Mikrobiologi Kedokteran, Bina Rupa Aksara Jakarta.

Susana D, Magdalena Y, Eryando T dan Adi HK.2008. Abstrak: Kontaminasi bakteri pada makanan dan minuman yang dijajakan di kantin Universitas Indonesia.

Volk dan Wheeler. 1993. Mikrobiologi Dasar, Erlangga, Jakarta.

World Health Organization.2003. Background document : The Diagnosis, Treatment and Prevention of Typhoid Fever, WHO/V7B/03.07.Geneva : World Health Organization. 